\title{
Identification of inrush water recharge sources using hydrochemistry and stable isotopes: A case study of Mindong No. 1 coal mine in north-east Inner Mongolia, China
}

\author{
Zilong Guan ${ }^{1,2}$, Zhifeng Jia ${ }^{1,2,3, *}$, Zhiqiang Zhao ${ }^{1,2}$ and Qiying You ${ }^{1,2,3}$ \\ ${ }^{1}$ School of Environmental Science and Engineering, Chang'an University, Xi'an 710 054, People's Republic \\ of China. \\ ${ }^{2}$ Key Laboratory of Subsurface Hydrology and Ecological Effects in Arid Region, Ministry of Education, \\ Chang'an University, Xi'an 710 054, People's Republic of China. \\ ${ }^{3}$ Institute of Water and Development, Chang'an University, Xi'an 710 054, People's Republic of China. \\ *Corresponding author. e-mail: 409538088@chd.edu.cn
}

MS received 16 June 2018; revised 25 April 2019; accepted 24 May 2019; published online 15 July 2019

Rapid identification of inrush water sources is vital for the safe operation of a coal mine. Hydrogeochemical (fuzzy comprehensive evaluation method and cluster analysis method) and isotope analyses are applied to identify the inrush water sources of the Mindong No. 1 mine, which is located in north-east Inner Mongolia, China. The clustering analysis and isotope analysis results show that the inrush water sources are from aquifer 1 (A1), aquifer 2 (A2) and Yimin river. However, fuzzy comprehensive evaluation shows that the inrush water sources are from A2, aquifer 3 (A3) and Yimin river. Considering the hydrogeological conditions of the study area, it is concluded that the inrush water sources are A1, A2 and Yimin river, with mixing ratios of $30.8 \%, 60.6 \%$ and $8.6 \%$, respectively. The application of multiple methods makes the conclusion more reliable. Additionally, this study improves the speed and effectiveness of the identification of inrush water sources in coal mines and provides a practical reference for research related to mine water inrush to ensure the safe operation of coal mines.

Keywords. Coal mine; inrush water; stable isotope; hydrogeochemistry; recharge sources.

\section{Introduction}

In a mine exploration area, groundwater plays an important role, providing the required water for daily use, plant growth and mining activities (Idrysy and Connelly 2012; Sun et al. 2012). Groundwater is also a crucial factor for mining activities, and the amount of water in the mine affects the production and safety of the mine. As one of the five disasters (gas, dust, water, fire and roof) in coal mines, mine water inrush also poses a serious threat to the safety production of coal mines (Hanhu and Yunquan 2011; Lu et al. 2012; Wu et al. 2013a; Jun et al. 2018). The catastrophic consequences of loss of property and casualties are caused by water inrush in coal mines.

There have already been many coal mine water inrush events in China; therefore, the governance of coal mine water disasters is indispensable (Hanhu and Yunquan 2011; Li et al. 2014a, b). A method for accurately and quickly judging the cause and the sources of water inrush is a 
precondition to prevent water inrush. Many experts and scholars have performed much research in the field of mine water source identification (Chen et al. 2009; Dou et al. 2011; Jiao et al. 2014; Li et al. 2014b; Yang et al. 2016). The main identification methods are geological analysis, hydrodynamic analysis, hydrogeochemical analysis, water temperature analysis, geophysical exploration and isotope analysis. Hydrogeochemical methods are widely used in mine water source identification (Dou et al. 2011; Wang 2014; Xu et al. 2014; Zhang et al. 2014; Liu et al. 2015; Jun et al. 2018) due to their simple, fast and low-cost characteristics. Some analytical methods based on hydrogeochemical data are also developing gradually. Fuzzy comprehensive evaluation was used to identify inrush water sources, and the advantages and disadvantages of this method have been pointed out (Xu et al. 2014; Liu et al. 2015). The distance discrimination method was used to identify mine inrush water sources, and the results were verified through the grey relational analysis method (Zhou et al. 2010; Wang et al. 2011). An analytical hierarchy process was used to identify the inrush water sources of coal mines, and reasonable results were also obtained $(\mathrm{Wu}$ et al. $2013 \mathrm{a}, \mathrm{b})$. These methods have greatly promoted the development of mine water source identification theory, but they still have some defects. For the fuzzy comprehensive evaluation method, it is difficult to determine the membership degree and the weight, which influences the judgement result. For the distance discriminant method, it regards all discriminant variables as equally important and may exaggerate or ignore the function of some variables. For the weight of the analytic hierarchy process, it is difficult to determine accurate results in the case of too many indices and statistics. In addition, due to the differences in geological conditions, hydrological conditions, data volumes, etc., these methods have specific applicable conditions. Therefore, it is necessary to ensure the validity of the conclusion by using mutual verification for multiple methods.

The environmental isotope technique, especially stable isotopes ( $\delta \mathrm{D}$ and $\left.\delta^{18} \mathrm{O}\right)$, has good performance in analysing the origin and formation of groundwater in the main aquifer (AQ). It can not only determine the interconnection between groundwater, precipitation and surface water, but also analyse the supply sources and mixture ratio of groundwater (Jiao et al. 2014; Guo et al. 2015; Maruyama and Kato 2017; Chafouq et al. 2018; Joshi et al. 2018; Xu et al. 2018; Yi et al. 2018). However, compared with the hydrogeochemistry method, isotope analysis is less used in coal mine enterprises independently due to its high cost, especially when there are more sample data. In summary, most of the existing studies are based on hydrochemical composition and isotope analysis to identify water sources, and the interpretation of water chemical data is not comprehensive enough. Therefore, for a specific coalfield, it is extremely necessary to accurately determine the water sources through the mutual verification of isotope and hydrogeochemical analyses. In this paper, we used the Mindong No. 1 mine, north-east Inner Mongolia, China, as an example. This study focused on the characteristics of hydrogen and oxygen isotopes and hydrogeochemistry and attempted to identify the inrush water sources of the first mining face of the Mindong No. 1 mine. The research first analysed the hydrogeological conditions and hydrogeochemical characteristics of water samples in the study area. Second, two different hydrogeochemical analysis methods and isotope techniques were applied to identify the inrush water sources of the first mining face of the Mindong No. 1 mine. The water sources were determined after comparisons among the different methods above, as well as through local hydrogeological conditions analysis. Thereafter, the mixing ratio of the inrush water sources was calculated. Each method has advantages and disadvantages, and the combination of multiple methods provides more reliable results. Moreover, the novel approach of applying hydrogeochemistry together with stable oxygen and hydrogen isotopes to identify water sources can offer a scientific reference for solving the problem of mine water inrush and thereby improve the safety and operational benefit of coal mines.

\section{Hydrogeological conditions of the study area}

Located on the western slope of Greater Khingan, the Mindong mining area is on the east side of the middle reaches of the Yimin river in Hulunbuir grassland. The Yimin coalfield is located in the north-eastern Yimin basin, which belongs to a sedimentary sag basin. The mine output scale is 18 million tons per year. The earliest mining area is the Mindong No. 1 mine (figure 1). The AQs are the Quaternary sandy gravel and medium to coarse sand AQ and the Yimin formation AQ composed of coal seams interlayered with sandy conglomerate 


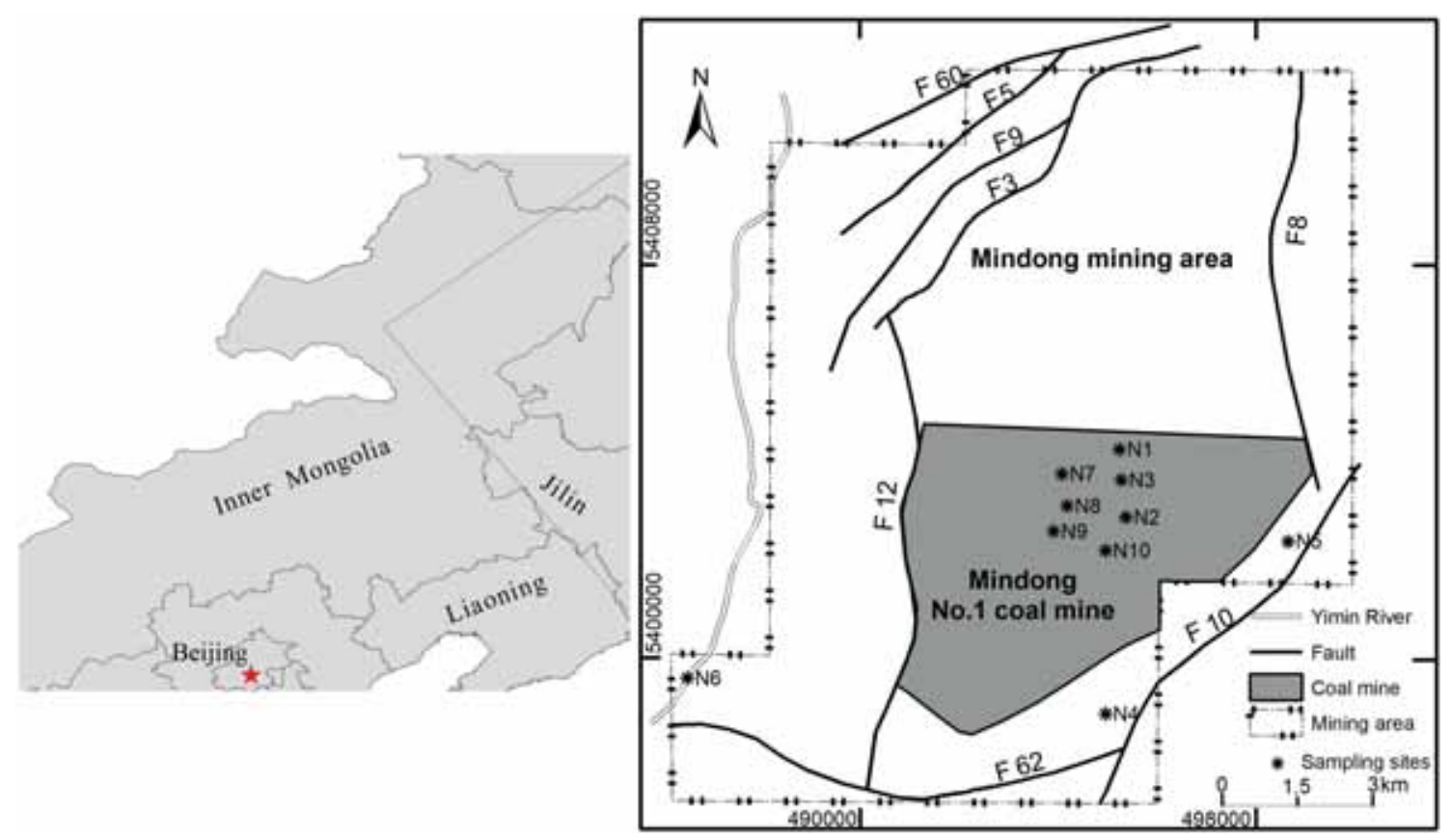

Figure 1. Map showing the location of the study area and sampling sites.

and medium to coarse sandstone. Among them, the AQs of the Yimin formation are composed of the coal seam 15 roof with interlayered sand and conglomerate-sandstone (A1), the coal seam group 16 roof with conglomerate-sandy conglomerate deposits (A2) and coal seam 16 interlayered with breccia-sandy conglomerate deposits (A3). Water bursting occurred in the first mining face (No. 13S101), which was located at the upper part of A3 (figure 2). According to the hydrogeological survey report of the coal mining enterprises, the average thickness of AQ is approximately $57 \mathrm{~m}$, and it is cut by the Yimin river and has a close hydraulic connection with river water. The average thickness of A1 is approximately $46 \mathrm{~m}$, and it is in unconformable contact with AQ. A1 is a direct waterfilling AQ for coal seam 15. The average thickness of A2 is approximately $55 \mathrm{~m}$, and the formation rocks are tuff and mud cement. A2 is an indirect water-filling AQ for coal seam 16-3 and is widely recharged through water conductive faults. The average thickness of A3 is approximately $38 \mathrm{~m}$ and A3 is the direct water-filling AQ for coal seam 16-3. The water abundance is good for the AQ, A1 and A 3 and extremely good for A2. In addition, there are 20 composite faults, and almost all are normal faults, which makes the hydrogeological conditions more complicated. The connection channels among the AQs are the skylight between the AQs and water conductive faults. The first mining face is

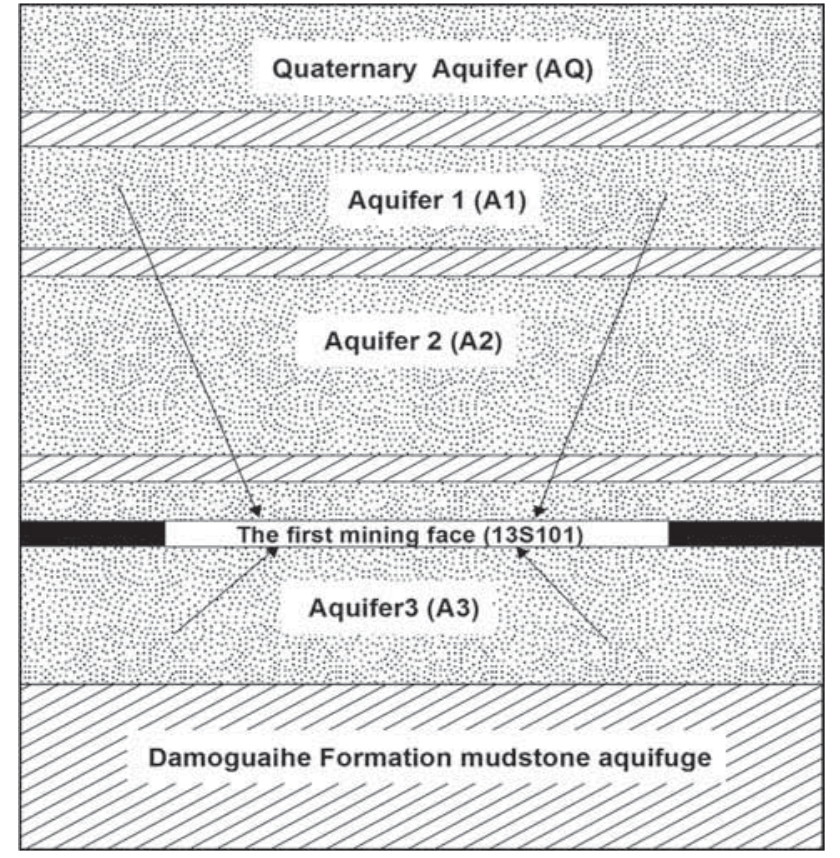

Figure 2. Map of the geological and groundwater AQ system in the mining area.

located in A3, and as production proceeds, the water in A3 is close to drained. However, the amount of water inflow in the first mining face is still very large, which has seriously affected production activities. Therefore, the main probable sources of water inflow are A1, A2, A3, AQ and Yimin river. 


\section{Data and methodology}

\subsection{Water sampling and analysis}

Samples of all types of water were collected from 1 November 2017 to 24 November 2017. A total of 10 samples were collected from AQ, A1, A2, A3 and Yimin river, and ground water samples were collected through drain bores or well bores specially designed for sampling. Among the samples, water sample N6 is from the Yimin river, N4 and N5 are from the AQ, N8 is taken from A1, N1, N9 and $\mathrm{N} 10$ are from A2, and N2 and N7 belong to A3. The number of water samples from different water sources is listed in table 1 . The water chemistry and isotopic analyses were performed in the Key Laboratory of Groundwater Science and Engineering of the Ministry of Land and Resources. The water chemical test was carried out by using an ion chromatograph (DX-120) with a relative error of $1 \%$. The stable isotopic compositions $(\delta \mathrm{D}$ and $\left.\delta^{18} \mathrm{O}\right)$ were determined by using an ultra-high precision liquid water and water vapour isotope analyser (Picarro L2130i) with a relative error of $0.2 \%$ for oxygen and $1 \%$ o for deuterium. The isotopic results were reported with respect to Vienna Standard Mean Ocean Water (VSMOW) distributed by the International Atomic Energy Agency (IAEA). The laboratory analysis results are shown in table 1.

\subsection{Analysis of hydrogeochemical characteristics}

Tri-linear diagrams are the most commonly used tools for revealing the hydrogeochemical characterisation of a chemical data set (Zhang et al. 2006; Li et al. 2014a). With the great advantage of plotting a large number of data points on one graph, a Piper diagram (Piper 1944) gives the hydrogeochemical facies of samples. In this study, the hydrogeochemical characteristics of water were analysed by a Piper diagram drawn in $\mathrm{Aq} \bullet \mathrm{QA}{ }^{\circledR}$ (RockWare, Inc. 2005).

\subsection{Fuzzy comprehensive evaluation}

Fuzzy comprehensive evaluation was applied to identify the sources of inrush water. Based on fuzzy mathematics, fuzzy comprehensive evaluation can transform qualitative evaluation into quantitative evaluation through the membership theory.

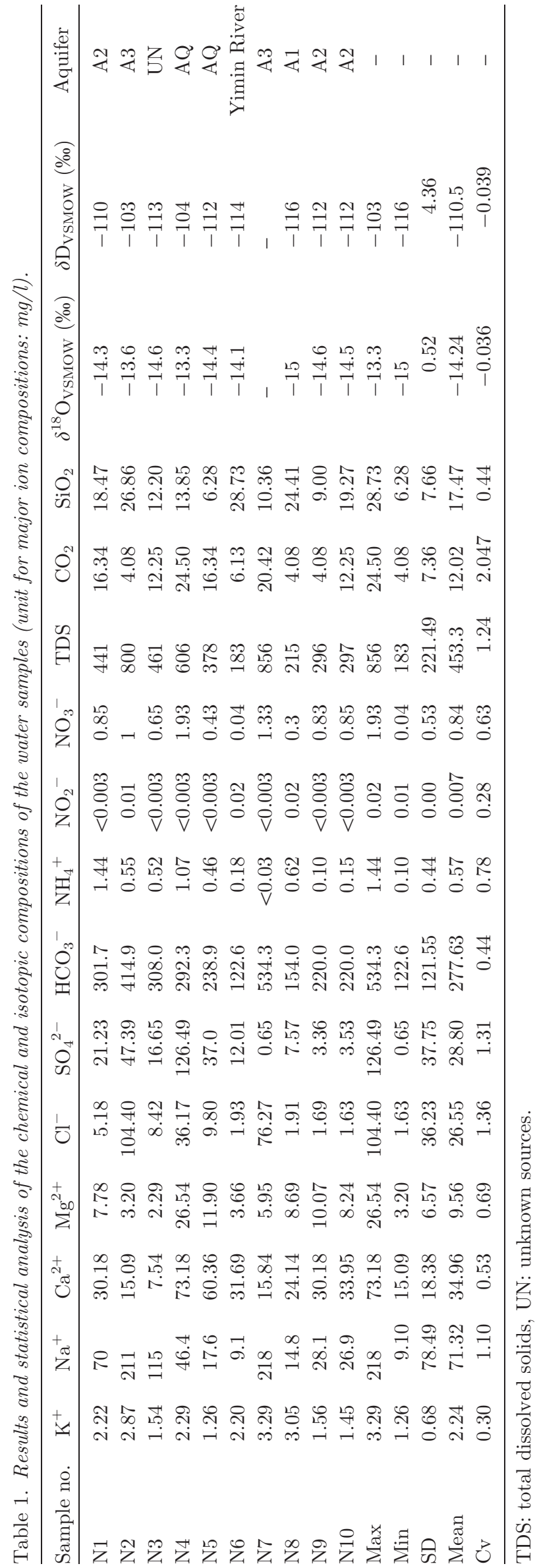


Therefore, it was widely used in previous studies (Yu et al. 2007; Liu et al. 2015).

The main steps of fuzzy comprehensive evaluation are as follows.

(1) Establish the factor set $U$ :

$$
U=\left(u_{1}, u_{2}, u_{3}, \ldots, u_{m}\right),
$$

where $u_{i}$ with $i=1,2,3, \ldots, m$ are the influence factors.

(2) Build the fuzzy weighting set $A$ :

$$
e_{i}=\frac{\left|x_{i}-a_{i}\right|}{a_{i}}
$$

where $x_{i}$ is the measured value of the factor indices in the inrush water sample, $a_{i}$ is the statistical average of the factor indices in each $\mathrm{AQ}$ and $\sum_{i=1}^{m} e_{i}=1$ :

$$
A=\left(e_{1}, e_{2}, e_{3}, \ldots, e_{m}\right) .
$$

(3) Build the evaluation set $V$ :

$$
V=\left(v_{1}, v_{2}, v_{3}, \ldots, v_{n}\right) .
$$

(4) Calculate the fuzzy relationship $R$ (based on lower semi-trapezoid distribution function):

$$
R=\left[\begin{array}{cccc}
r_{11} & r_{12} & \ldots & r_{1 n} \\
r_{21} & r_{22} & \ldots & r_{2 n} \\
\vdots & \vdots & \ddots & \vdots \\
r_{m 1} & r_{m 2} & \ldots & r_{m n}
\end{array}\right]
$$

(5) Calculate the comprehensive evaluation matrix $B$ :

$$
B=A \circ R=\left(b_{1}, b_{2}, b_{3}, \ldots, b_{n}\right) .
$$

Based on the fuzzy method, the evaluation results are calculated as follows:

$$
b_{j}=\bigvee_{1}^{m}\left(e_{i} \bigwedge r_{i j}\right),
$$

where $j$ is from 1 to $n$.

A greater value in matrix $B$ indicates that the inrush water sample has a higher degree of membership.

\subsection{Clustering analysis}

Based on cluster analysis, the degree of similarity can be calculated. Samples were classified into different groups according to the degree of affinity. Thus, cluster analysis is suitable for the identification of water sources (Güler et al. 2002; Omo-Irabor et al. 2008; Belkhiri et al. 2010). In the process of clustering analysis, the Euclidean distance is selected to calculate the distance between variables, and the group-average method is applied to cluster all varieties. Clustering analysis is carried out through MATLAB 2015b.

\subsection{Meteoric water line}

The meteoric water line reveals the relationship between $\mathrm{D}$ and ${ }^{18} \mathrm{O}$ in rain and is regarded as a reference for the evaluation of relative enrichment or depletion in isotopic content, including evaporation, condensation and the mixing of two or more water bodies with different isotopes (Chen et al. 2015; Maruyama and Kato 2017). In 1961, by analysing the isotopic data of global precipitation samples, Craig (1961) obtained the 'Global Meteoric Water Line' (GMWL). Then, the GMWL was corrected by the International Atomic Energy Agency (IAEA) $10 \mathrm{yr}$ later (Yurtsever 1975). The fixed linear relationship is as follows:

$$
\delta \mathrm{D}=8.13 \delta^{18} \mathrm{O}+10.8
$$

However, the meteoric water line tends to deviate from the GMWL in different regions (Rozanski et al. 1993). Based on the hydrogen-oxygen isotope data of precipitation collected from the Global Network of Isotopes in Precipitation, Liang et al. (2017) defined the meteoric line of the Hulunbuir region (hereafter abbreviated as HMWL), and it is expressed as follows:

$$
\delta \mathrm{D}=7.59 \delta^{18} \mathrm{O}-3 .
$$

\section{Results}

\subsection{General hydrogeochemical characteristics}

The physiochemical parameters and statistical analysis results are shown in table 1 . According to the table, the variation coefficients of $\mathrm{Cl}^{-}$and $\mathrm{SO}_{4}{ }^{2-}$ were the largest (1.36 and 1.31 , respectively). The values of the main indices of the inrush water sample (N3) were close to the mean (table 1), indicating that the water sample N3 may be mixed with a variety of sources.

As depicted in the Piper diagram (figure 3), $\mathrm{HCO}_{3}{ }^{-}$was the predominant anion in almost all water samples. $\mathrm{Cl}^{-}$was similar to $\mathrm{SO}_{4}{ }^{2-}$, both with low contents, reflecting the relatively low degree of the water-rock interaction in local groundwater 


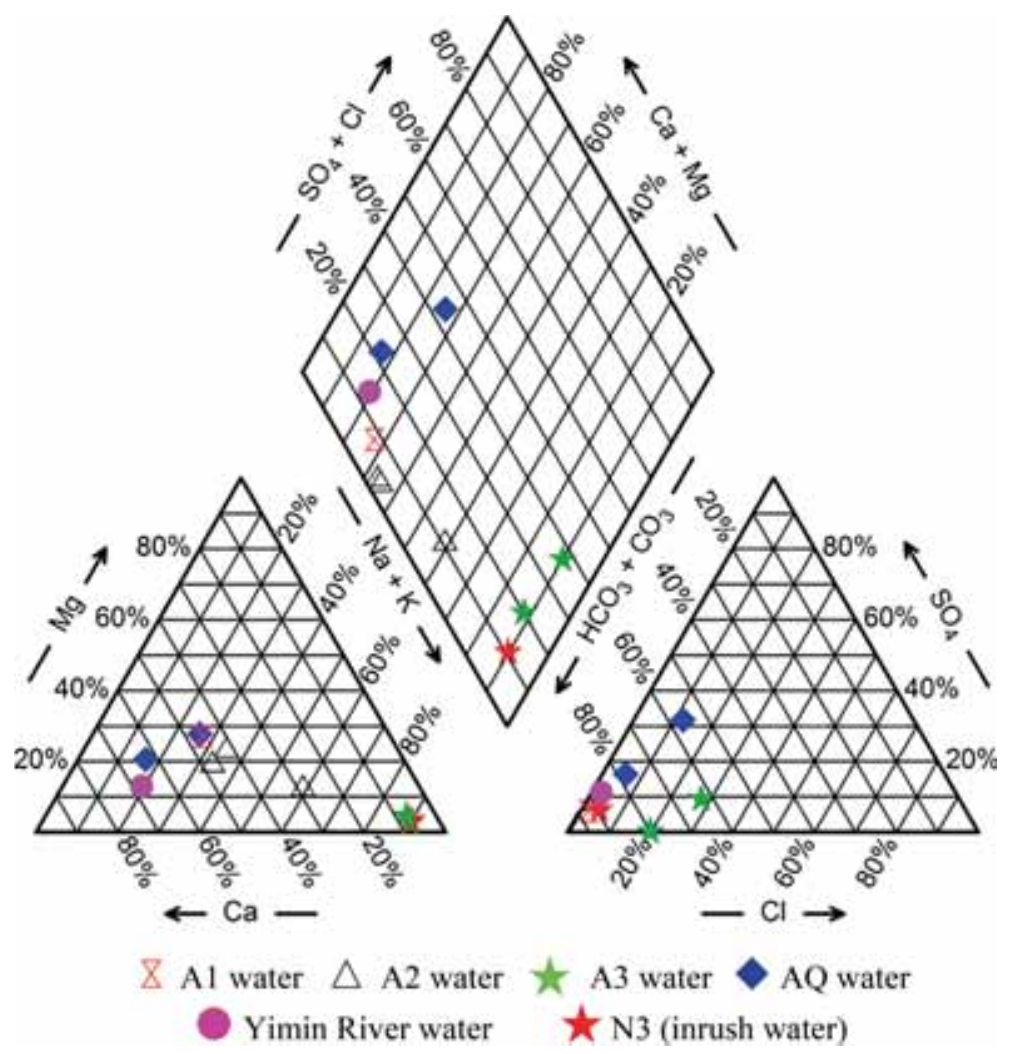

Figure 3. Piper diagram of the water samples from different sources.

systems. $\mathrm{Na}^{+}\left(\mathrm{K}^{+}\right)$are the predominant cations in $\mathrm{A} 3$ and the inrush water sample and $\mathrm{Ca}^{2+}$ is the dominant ion for the rest of the water bodies. The hydrogeochemical types of $\mathrm{AQ}, \mathrm{A} 1$ and the Yimin river water were characterised by $\mathrm{Ca}-\mathrm{HCO}_{3}$, while the water type of $\mathrm{A} 3$ and the inrush water sample (N3) fell into the category of $\mathrm{Na}-\mathrm{HCO}_{3}$. The water types of $\mathrm{A} 2$ varied with depth due to its internal lithologic changes so that there were two water types of $\mathrm{Ca}-\mathrm{HCO}_{3}$ and $\mathrm{Na}-\mathrm{HCO}_{3}$. As shown in the Piper diagram, from the perspective of the anion content, A1, A2 and the Yimin river water were very close to N3, all with high $\mathrm{HCO}_{3}{ }^{-}$content and low $\mathrm{Cl}^{-}$and $\mathrm{SO}_{4}{ }^{2-}$ contents. By contrast, from the perspective of cation content, the nearest water source to the N3 was A3, followed by A2, both with high $\mathrm{Na}^{+}$content. According to the position of each water sample in the Piper diagram, A3 is most similar to N3, followed by A2 and A1. That is, A3 is most likely to be the water source.

\subsection{Identification of inrush water sources}

\subsubsection{Fuzzy comprehensive evaluation}

After the probable water sources were determined based on the hydraulic connection, an evaluation set, $V=(\mathrm{A} 1, \mathrm{~A} 2, \mathrm{~A} 3, \mathrm{AQ}$, Yimin river $)$, was established. Based on the calculation procedure described in the paragraphs above, the evaluation index is $B=(0.015,0.161,0.161,0.131,0.150)$ with the data obtained from the laboratory. The three water sources with the highest membership degree of inrush water (N3) are A2, A3 and Yimin river.

\subsubsection{Clustering analysis}

The clustering pedigree for all water samples is shown in figure 4(a). Considering that the water sources are certain types of water, rather than water samples, the background values of each water source are represented by the average of various water samples in the same water source. Cluster analysis based on water source types was also conducted, and the clustering pedigree of each water source type is shown in figure 4(b). As depicted in figure 4(a), the water samples that were clustered together in one cluster with N3 first were N8, N6, N10 and N9. Obviously, N8 and N6 belong to A1 and Yimin river, respectively, and both N9 and N10 belong to A2. It is noteworthy that N1, which is also collected from A2, is excluded from the cluster. The reason might be that 

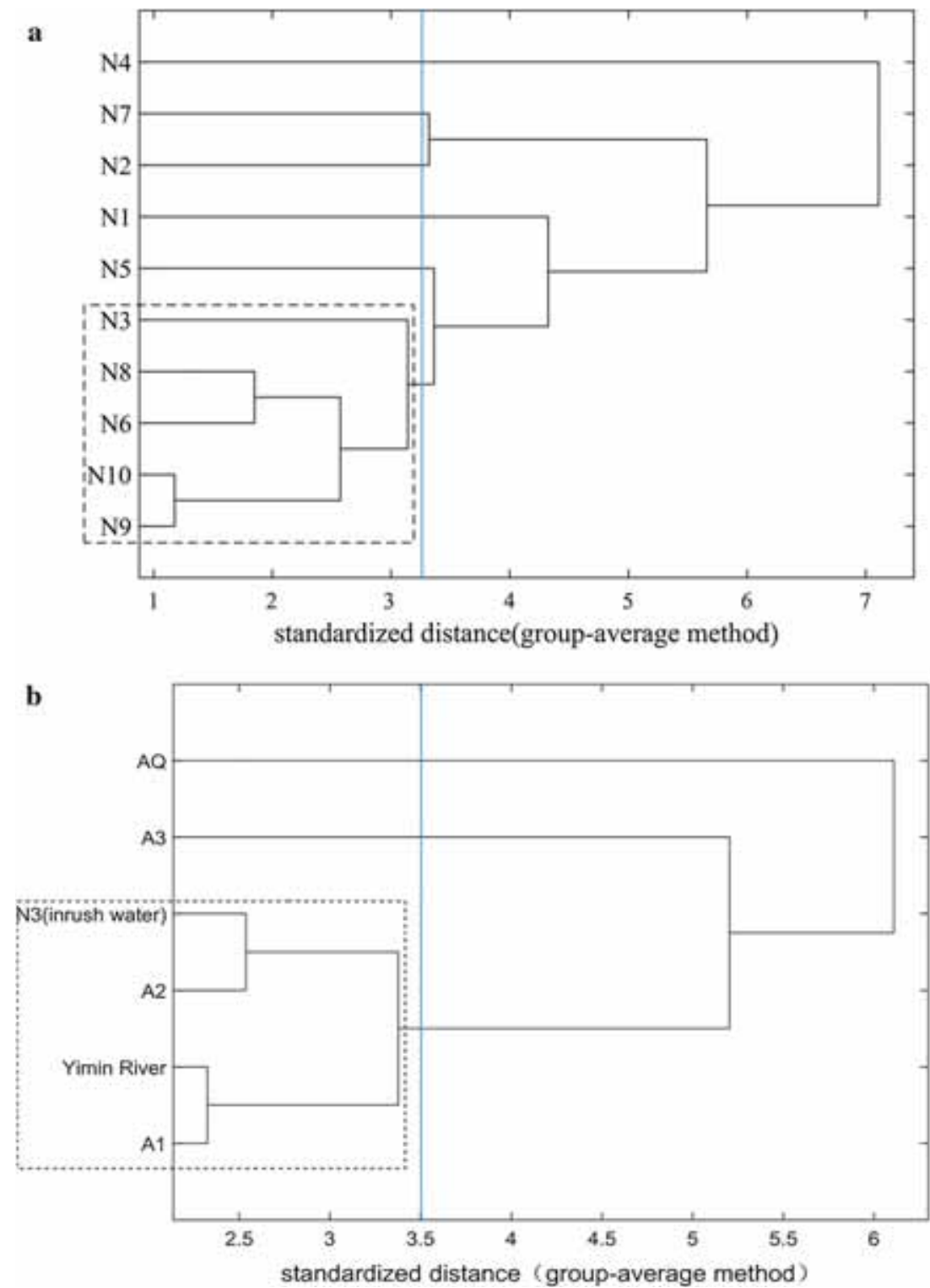

Figure 4. Dendrograms showing classification (a) for all water samples and (b) for different water bodies.

the A2 is thick (nearly $60 \mathrm{~m}$ ), and due to the cementation of mud and tuff, the lithology varies, which leads to differences in the chemical composition of the groundwater. This result can also be reflected through the water types mentioned in the general hydrogeochemical characteristics part. Therefore, A1, A2 and Yimin river are most likely inrush water sources, which can also be explicitly drawn from figure 4(b). In particular, figure 4(b) also shows that A2 is most similar to N3, followed by A1 and Yimin river.

\subsubsection{Isotopic analysis}

As demonstrated in figure 5(a), the slope and intercept of the HMWL were slightly lower than those of the GMWL, demonstrating that precipitation in the study area experienced relatively slight secondary evaporation of raindrops during their descent to the ground. This phenomenon was well documented in the semi-arid regions. Most of the water samples are distributed along the HMWL, with the exception of A3 and Yimin river, which are far from the HMWL - one above the line and one below the line - indicating that the recharge of $\mathrm{AQ}, \mathrm{A} 2$ and $\mathrm{A} 1$ is closely related to atmospheric precipitation, while A3 and Yimin river have less of a relationship with atmospheric precipitation. The reason why the Yimin river is far from the line may be that river bodies undergo relatively significant evaporation. In addition, the region entered the dry season in October, and 

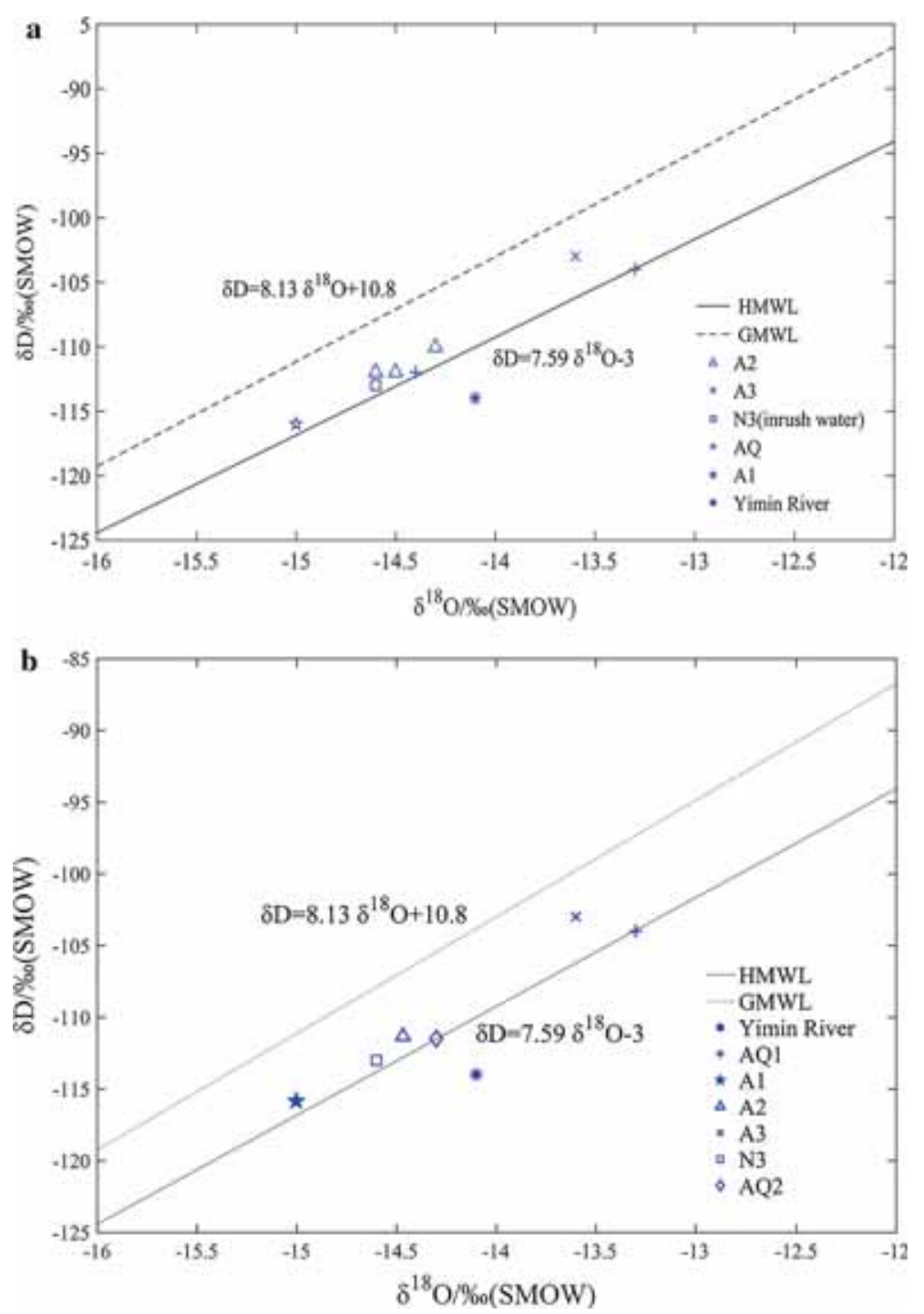

Figure 5. Cross plot of $\delta \mathrm{D}_{\text {VSMOW }}$ vs. $\delta^{18} \mathrm{O}_{\mathrm{VSMOW}}(\mathbf{a})$ for all water samples and (b) for different water bodies.

according to the hydrogeological prospecting reports of the coal mine, the Yimin river receives recharge from $\mathrm{AQ}$ in the dry season, which has a higher isotopic content (figure 5). A possible reason for the deviation of A3 is that the Yimin basin where Mindong No. 1 mine is located is an ancient sedimentary sag basin, and A3 belongs to the Cretaceous Yimin formation. The tectonic environment of the sedimentary basin is favourable for water-rock interactions (Shi et al. 2012; Ma et al. 2013; Fallick et al. 2016). As also shown in the relationship diagram of total dissolved solids (TDS) with $\delta^{18} \mathrm{O}$ and $\delta \mathrm{D}$ (figure $6 \mathrm{a}$ and $\mathrm{b}$ ), the concentration of ${ }^{18} \mathrm{O}$ and $\mathrm{D}$ formation in water increases with increasing TDS. High TDS in groundwater means intense water-rock interaction (Shi et al. 2012). Therefore, the higher $\delta \mathrm{D}$ in A3 is due to the isotope exchange between groundwater and hydrogen sulphide, hydrocarbons and hydrated minerals, and the higher $\delta^{18} \mathrm{O}$ in $\mathrm{A} 3$ is also due to the isotope exchange between groundwater and surrounding rocks. To study the relationship between the inrush water sample (N3) and various water sources, the mean values of all kinds of water sources except AQ were plotted in figure 5(b) because the two water samples of $\mathrm{AQ}$ are quite different. As depicted in figure 5(b), the isotopic content of $\mathrm{N} 3$ is different from that of other water samples. In addition, the isotopic composition of A1 is most depleted, and the reason might be that according to the geological report of the study area, A1 has an unconformable contact with AQ, i.e., A1 has direct surface exposure, so A1 can accept mixed recharge of atmospheric precipitation, snow meltwater in spring and groundwater in AQ. From the perspective of isotopic composition, A2 is the most similar to the inrush water (N3); thus, A2 is undoubtedly one of the recharge 

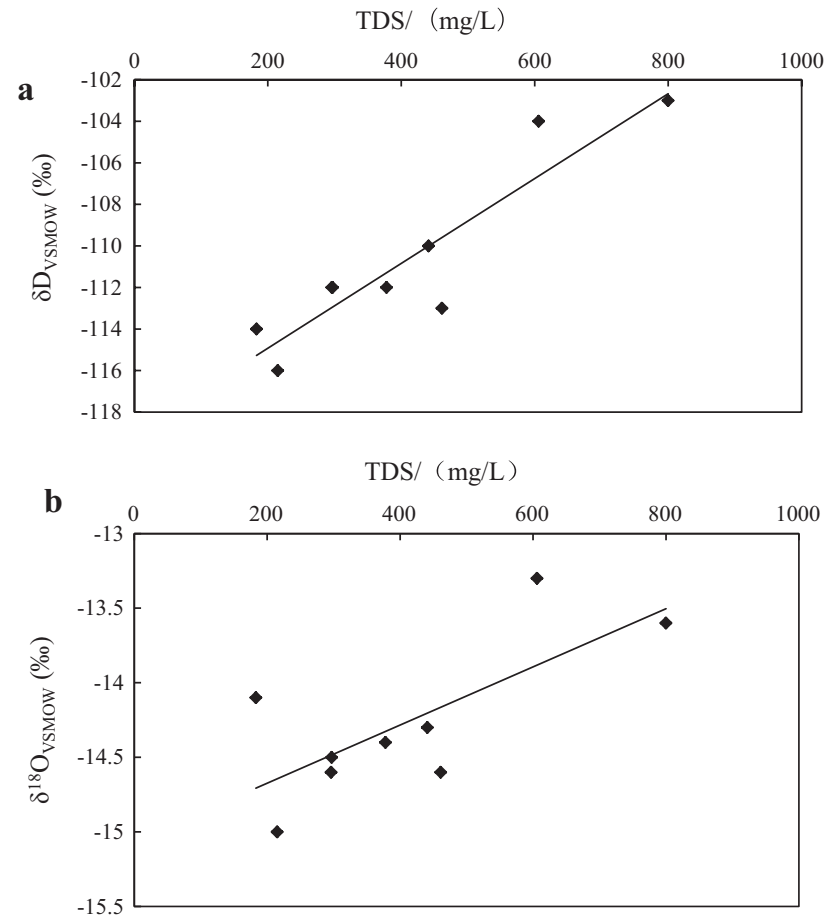

Figure 6. Variations in TDS with (a) $\delta \mathrm{D}_{\text {VSMOW }}$ and (b) $\delta^{18} \mathrm{O}_{\mathrm{VSMOW}}$ of the formation of water in the Mindong No. 1 coal mine.

sources of N3. Notably, the $\delta^{18} \mathrm{O}$ and $\delta \mathrm{D}$ in $\mathrm{A} 2$ $(-14.46 \%,-111.33 \%)$ are higher than those in N3 $(-14.6 \%,-113 \%$ ). If N3 is a mixed water sample, according to the principle of taking the average after mixing, there definitely exists a water source with values of both $\delta^{18} \mathrm{O}$ and $\delta \mathrm{D}$ lower than those in $\mathrm{N} 3$, and $\mathrm{A} 1(-15 \%,-116 \%)$ is the only AQ with values of both $\delta^{18} \mathrm{O}$ and $\delta \mathrm{D}$ lower than those in N3. Comparatively, the Yimin river only has a lower $\delta \mathrm{D}$ value than that in N3. Therefore, A1 is most likely one of the recharge sources for N3, and the Yimin river may also be one of the water sources. Nevertheless, the isotopic composition of the remaining water bodies and the inrush water sample (N3) are relatively different. Based on the analysis above, it is almost certain that N3 is a mixed water sample, and its water sources contain at least A2 and A1. In addition, referencing the position of the point plotted in figure 5(b), A2 accounted for the largest proportion of inrush water.

\section{Discussion}

\subsection{Determination of water sources}

To study the inrush water sources in the first mining face of Mindong No. 1 mine, fuzzy comprehensive evaluation, clustering analysis and isotope analysis were used to identify the water source. The results should be combined with the hydrogeological conditions of the coal mine to determine the water sources.

The fuzzy comprehensive evaluation shows that the most likely inrush water sources are A2, A3 and the Yimin river. By contrast, clustering analysis shows that inrush water is most likely from A1, A2 and Yimin river. From the isotopic analysis, A2 is most similar to N3, followed by AQ2. However, the other two methods show that AQ has little similarity to N3. Moreover, there is a large difference between AQ1 and AQ2, and AQ1 is very different from N3 in isotopic composition, so it is almost impossible for $\mathrm{AQ}$ to be a water inrush source. Obviously, the result of fuzzy comprehensive evaluation is slightly different from other results, so analysis from the perspective of hydrogeological conditions was urgently necessary. A small portion of the supply sources of the coal-bearing AQ (mainly A1 and A2) of the Mindong No. 1 coal mine is the direct infiltration of atmospheric precipitation through the outcrop of the coal system. A2 has a very close hydraulic connection with $\mathrm{A} 3$, and it is recharged by water from the water conductive faults (F12 and F8) on both the east and the west sides, and is also supplied by the roof AQ (A1). According to the hydrogeology prospecting report of the Mindong No. 1 mine in the Yimin coal mine in the Inner Mongolia autonomous region, the results obtained through the underground electrical method and ground transient electromagnetic detection demonstrated that inrush water in the first mining face was mainly from A2. Furthermore, the fractures in the vicinity of the mining face are relatively developed, with the upper and lower connected trends, which also enhance the hydraulic connection of the upper and lower AQs. Along with the production activities and the exploration work, the number of boreholes is increasing, and A1, A2 and A3 are available for mutual supply through boreholes that are not sealed properly. In addition, according to the hydrogeological survey report of the coal mine and coal mine production department, the Yimin basin, where the coal mine is located, belongs to the sedimentary sag basin, and the original water in A3 is sedimentary water. Moreover, as the coal mining is continuously developed, A3 is close to being drained; thus, A3 is unlikely to be a source of water inrush.

From the perspective of hydrogen-oxygen isotopes, A2 is closest to N3, but they are not equal, so the inrush water is mixed water, and A2 is the 
main water source, which is also embodied in the other two methods. For $\delta^{18} \mathrm{O}$ and $\delta \mathrm{D}$ in all the water sources, only those in A1 are less than those in the inrush water; thus, the inrush water, as mixed water, must contain A1. As shown in figure 5(b), the inrush water (N3) is located in a triangle formed by A1, A2 and the Yimin river water, which is consistent with the characteristics of the three-component mixing of groundwater. Therefore, the inrush water sources were A1, A2 and Yimin river.

In general, the above analysis indicated that the inrush water was supplied by A1, A2 and Yimin river, and A2 was the uppermost source. This result has also been recognised by the coal mine department of production safety supervision.

\subsection{Partition of sources for inrush water}

The isotopic and hydrogeochemical data and the hydrogeological conditions of the mine suggest that the sources of inrush water are mainly from A1, A2 and Yimin river. However, the proportion of the three water sources in the inrush water is variable. Based on the law of conservation of mass, a segmentation model was built for inrush water in the mine using the end-member mixing analysis method, which can be expressed as:

$$
\left\{\begin{array}{l}
\delta \mathrm{D}_{\mathrm{A}} \times R_{1}+\delta \mathrm{D}_{\mathrm{B}} \times R_{2}+\delta \mathrm{D}_{\mathrm{C}} \times R_{3}=\delta \mathrm{D}_{\mathrm{M}}, \\
\delta^{18} \mathrm{O}_{\mathrm{A}} \times R_{1}+\delta^{18} \mathrm{O}_{\mathrm{B}} \times R_{2}+\delta^{18} \mathrm{O}_{\mathrm{C}} \times R_{3}=\delta^{18} \mathrm{O}_{\mathrm{M}}, \\
R_{1}+R_{2}+R_{3}=1,
\end{array}\right.
$$

where A, B and C are A1 water, A2 water and Yimin river water, respectively, $\mathrm{M}$ is the mixture of inrush water, $\delta \mathrm{D}_{\mathrm{A}}, \delta \mathrm{D}_{\mathrm{B}}$ and $\delta \mathrm{D}_{\mathrm{C}}$ are the concentrations of $\mathrm{D}$ in end members $\mathrm{A}, \mathrm{B}$ and $\mathrm{C}$, respectively, $\delta^{18} \mathrm{O}_{\mathrm{A}}$, $\delta^{18} \mathrm{O}_{\mathrm{B}}$ and $\delta^{18} \mathrm{O}_{\mathrm{C}}$ are the concentrations of ${ }^{18} \mathrm{O}$ in end member $\mathrm{A}, \mathrm{B}$ and $\mathrm{C}$, respectively, $\delta \mathrm{D}_{\mathrm{M}}$ and $\delta^{18} \mathrm{O}_{\mathrm{M}}$ are the concentrations of $\mathrm{D}$ and ${ }^{18} \mathrm{O}$ in the inrush water, respectively, and $R_{1}, R_{2}$ and $R_{3}$ are the proportions of $\mathrm{A}, \mathrm{B}$ and $\mathrm{C}$ in mixed water, respectively.

By applying oxygen and hydrogen isotopic data to the mass balance equation derived above, we propose that the proportions of A1, A2 and Yimin River are $30.8 \%, 60.6 \%$ and $8.6 \%$, respectively, in the inrush water.

\subsection{Evaluation of methods}

Isotope analysis has high precision in water source identification (Jiao et al. 2014; Zhang et al. 2014;
Guo et al. 2015; Maruyama and Kato 2017; Joshi et al. 2018; Yi et al. 2018), which is also reflected in this study. Among the results of the three methods, the fuzzy comprehensive evaluation is slightly different from the others. Two important reasons could have caused this result. One is that the process of determining the membership degree in fuzzy comprehensive evaluation is obviously defective, and its computational accuracy is affected by the results of the hydrochemical analysis in the laboratory, which is also reflected in the previous research. The other one, and perhaps the most important, is that the water inrush point is located in A3, and when the water in the upper AQ flows through A3 to recharge the water inrush point, the water will dissolve a certain number of minerals in A3, resulting in the extremely close relationship between the composition of chemical ions in water and the lithology of AQs. Thus, even if the water yield in A3 is very small, the hydrogeochemical characteristics of the inrush water are similar to A3 (figure 3), affecting the hydrogeochemical analysis results. In addition, in the case of a small amount of data, clustering analysis is more likely to obtain reasonable results (Kaijun et al. 2009; Seaman et al. 2014). Therefore, the result of the cluster analysis was consistent with the isotope analysis and was regarded as the final result. In conclusion, when the amount of hydrogeochemical data is relatively small, cluster analysis, with high reliability, is more suitable than fuzzy comprehensive evaluation in the identification of water sources.

According to the results obtained from the inrush water source identification, we estimated that most of the inrush water is from A2 and A1, but there was still a small amount of water from the Yimin river. The way by which the Yimin river supplies the water inrush point and its evolution in the future were not studied and could be the target of future research. In addition, although the results serve as a good guide, limitations on the data still exist in the study. The number of water samples has a certain effect on the research, and the accuracy of the results will increase with the amount of water samples.

\section{Conclusion}

In this study, water chemistry analysis methods (fuzzy comprehensive evaluation and cluster analysis) and isotope analysis $\left(\delta^{18} \mathrm{O}\right.$ and $\left.\delta \mathrm{D}\right)$ were 
applied to identify the recharge sources of inrush water in Mindong No. 1 mine. Our results reveal that all water bodies, including groundwater and surface water, are identified as $\mathrm{Ca}-\mathrm{HCO}_{3}$ and $\mathrm{Na}-\mathrm{HCO}_{3}$ water types, and as the depth increases, the water type changes from $\mathrm{Ca}-\mathrm{HCO}_{3}$ to $\mathrm{Na}-\mathrm{HCO}_{3}$, indicating that the deep groundwater chemistry characteristics are controlled by waterrock interactions.

The mutual verification of the cluster analysis method, fuzzy comprehensive evaluation method and isotope analysis, together with the analysis of hydrogeological conditions, indicate that the recharge sources for inrush water are A1, A2 and Yimin river, with proportions of $30.8 \%, 60.6 \%$ and $8.6 \%$, respectively. The high reliability of the isotope analysis is also reflected in this study. Through mutual verification, the isotopic method has provided conducive information and further confirmed the reliability of the clustering analysis results in this mining area. In addition, the clustering analysis is more reliable than the fuzzy comprehensive evaluation method with regard to this mining area where the amount of sampling data was relatively small.

This research provides a practical reference for studies related to mine water inrush and other monitoring activities concerning the identification of water origins. This study also provides a useful engineering technique for better operation of coal mines and their safety. For a certain coal mine, a suitable water source identification method could be found, by which the inrush water sources are identified quickly and effectively using hydrogeochemical data accumulated over many years, ensuring the safe production of the coal mine, as well as economic benefits.

\section{Acknowledgements}

This work was supported by '111' Intellect Importation Project (B08039), Fundamental Research Funds for the Central Universities (310829161003 and 310829161010), the Special Fund for Basic Scientific Research of Central Colleges (310829163405), Xi'an Construction Science and Technology Planning Project (SJW2017-11), the open fund of Key Laboratory of Subsurface Hydrology and Ecological Effect in Arid Region of Ministry of Education (No. 300102298502) and the National Natural Science Foundation of China (41761144059).

\section{References}

Belkhiri L, Boudoukha A, Mouni L and Baouz T 2010 Application of multivariate statistical methods and inverse geochemical modeling for characterization of groundwater A case study: Ain Azel plain (Algeria); Geoderma 159(3-4) 390-398, https://doi.org/10.1016/j.geoderma.2010.08.016.

Chafouq D, El Mandour A, Elgettafi M, Himi M, Chouikri I and Casas A 2018 Hydrochemical and isotopic characterization of groundwater in the Ghis-Nekor plain (northern Morocco); J. Afr. Earth Sci. 139 1-13, https://doi.org/10. 1016/j.jafrearsci.2017.11.007.

Chen H, Li X, Liu A and Peng S 2009 Identifying of mine water inrush sources by Fisher discriminant analysis method; J. Cent. South Univ. (Sci. Technol.) 40(04) 1114-1120.

Chen T, Chen H, Han L, Xing X and Fu Y 2015 Stable isotopes characters of soil water movement in Shijiazhuang city; Env. Sci. 36(10) 3641-3648 (in Chinese).

Craig H 1961 Isotopic variations in meteoric waters; Science 133 1702-1703.

Dou H, Ma Z, Cao H, Liu F, Hu W and Li T 2011 Application of isotopic and hydro-geochemical methods in identifying sources of mine inrushing water; Min. Sci. Technol. (China) 21(3) 319-323, https://doi.org/10.1016/j.mstc.2011.05. 021.

Fallick A E, Melezhik V A, Brasier A T and Prave A R 2016 Unusual, basin-scale, fluid-rock interaction in the Palaeoproterozoic Onega basin from Fennoscandia: Preservation in calcite $\delta^{18} \mathrm{O}$ of an ancient high geothermal gradient; Precamb. Res. 281 224-235, https://doi.org/10.1016/j. precamres.2016.06.001.

Güler C, Thyne G D, McCray J E and Turner K A 2002 Evaluation of graphical and multivariate statistical methods for classification of water chemistry data; Hydrogeol. J. 10(4) 455-474, https://doi.org/10.1007/s10040-0020196-6.

Guo X, Feng Q, Liu W, Li Z, Wen X, Si J, Xi H, Guo R and Jia B 2015 Stable isotopic and geochemical identification of groundwater evolution and recharge sources in the arid Shule River Basin of Northwestern China; Hydrol. Processes 29(22) 4703-4718, https://doi.org/10.1002/hyp. 10495.

Hanhu L and Yunquan C 2011 Technologies of preventing coal mine water hazards for sustainable development in North China; Geotech. Geol. Eng. 29(1) 1-5, https://doi.org/10. 1007/s10706-010-9361-1.

Idrysy H E and Connelly R 2012 Water - The other resource a mine needs to estimate; Procedia. Eng. 46 206-212, https://doi.org/10.1016/j.proeng.2012.09.466.

Jiao Y, Wang G, Fan Y, Sun T, Zhao X, Shi Z, Ma L, Lu Z, Cui L and Lv L 2014 Distinguishing water sources of the abandoned mine in Fengfeng mining area by using hydrochemistry and hydrogen, oxygen isotopes; Quat. Sci. 34(05) 1054-1061 (in Chinese).

Joshi S K, Rai S P, Sinha R, Gupta S, Densmore A L, Rawat Y S and Shekhar S 2018 Tracing groundwater recharge sources in the northwestern Indian alluvial aquifer using water isotopes $\left(\delta^{18} \mathrm{O}, \delta^{2} \mathrm{H}\right.$ and $\left.{ }^{3} \mathrm{H}\right) ;$ J. Hydrol. 559 835-847, https://doi. org/10.1016/j.jhydrol.2018.02.056.

Jun Z, Duoxi Y and Yue S 2018 Multivariate matrix model for source identification of inrush water: A case study from 
Renlou and Tongting coal mine in northern Anhui province, China; In: IOP conference series: Earth and environmental science, Vol. 113, 012212, https://doi.org/10.1088/1755$1315 / 113 / 1 / 012212$.

Kaijun W, Baijie W and Liuqing P 2009 CVAP: Validation For cluster analyses; Data Sci. J. 8 88-93, https://doi.org/ 10.2481/dsj.007-020.

Li P, Wu J and Qian H 2014a Hydrogeochemistry and quality assessment of shallow groundwater in the southern part of the Yellow River alluvial plain (Zhongwei section), Northwest China; Earth Sci. Res. J. 18(1) 27-38, https://doi. org/10.15446/esrj.v18n1.34048.

Li S J, Wu Q, Cui F P, Zeng Y F and Wang G R 2014b Major characteristics of China's coal mine water disaster occurred in recent years; Appl. Mech. Mater. 501-504 336-340, https:// doi.org/10.4028/www.scientific.net/amm.501-504.336.

Liang L, Li C, Shi X, Sun B, Wang J and Zhou J 2017 Characteristics of hydrogen and oxygen isotopes of surface and groundwater and the analysis of source of lakewater in Hulun lake basin, inner Mongolia; Wetland Sci. 15(03) 385-390 (in Chinese).

Lu J, Li X, Gong F, Wang X and Liu J 2012 Recognizing of mine water inrush sources based on principal components analysis and fisher discrimination analysis method; China Saf. Sci. J. (CSSJ) 22(07) 109-115 (in Chinese).

Liu J, Wang J, Liu Y, Wu H and Zhou B 2015 Hydrochemistry analysis based on the source determination of coal mine water-bursts; J. Saf. Env. 15(01) 31-35 (in Chinese).

Ma X, Song Y, Liu S, Jiang L and Hong F 2013 Origin, age, and evolution of water in coal reservoirs: Evidence of halogen ions, stable isotopes, and ${ }^{129} \mathrm{I}$ (in Chinese); Sci. Sin. (Terrae) 43(10) 1699-1707.

Maruyama S and Kato H 2017 Identification of waters incorporated in Laguna lake, Republic of the Philippines, based on oxygen and hydrogen isotopic ratios; Water-Sui. 9(5) 328, https://doi.org/10.3390/w9050328.

Omo-Irabor O O, Olobaniyi S B, Oduyemi K and Akunna J 2008 Surface and groundwater water quality assessment using multivariate analytical methods: A case study of the Western Niger Delta, Nigeria; Phys. Chem. Earth $A / B / C$ 33(8-13) 666-673, https://doi.org/10.1016/j.pce.2008.06. 019.

Piper A M 1944 A graphic procedure in the geochemical interpretation of water analysis; Trans. Am. Geophys. Union 25(1) 27-39

Rozanski K, Araguás-Araguás L and Gonfiantini R 1993 Isotopic patterns in modern global precipitation; In: Climate change in continental isotopic records (eds) Swart P K, Lohmann K C, Mckenzie J and Savin S, American Geophysical Union, Washington, DC, USA, pp. 1-36.

Seaman S R, Pavlou M and Copas A J 2014 Methods for observed-cluster inference when cluster size is informative: A review and clarifications; Biometrics 70(2) 449-456, https://doi.org/10.1111/biom.12151.

Shi T, Cheng J, Xie X and Zhang X 2012 Isotopic characteristics of formation waters in the North of Songliao basin and its geological significances (in Chinese); Acta Sedim. Sin. 30(02) 399-404.

Sun W, Wu Q, Dong D and Jiao J 2012 Avoiding coal-water conflicts during the development of China's large coalproducing regions; Mine Water Environ. 31(1) 74-78, https://doi.org/10.1007/s10230-012-0173-9.

Wang S 2014 Identification of water bursting source based on hydrogeochemical characteristic in mixture effect of different aquifer; Min. Res. Dev. 34(03) 58-60 (in Chinese).

Wang X, Xu T and Huang D 2011 Application of distance discriminance in identifying water inrush resource in similar coalmine; J. China Coal Soc. 36(08) 1354-1358 (in Chinese).

Wu Q, Cui F, Zhao S, Liu S, Zeng Y and Gu Y 2013a Type classification and main characteristics of mine water disasters; J. China Coal Soc. 38(04) 561-565.

Wu Q, Fan S, Zhou W and Liu S 2013b Application of the analytic hierarchy process to assessment of water inrush: A case study for the No. 17 coal seam in the Sanhejian Coal Mine, China; Mine Water Environ. 32(3) 229-238, https:// doi.org/10.1007/s10230-013-0228-6.

Xu Y, Gao Y, Li W, Wei W and Liang L 2014 Prediction of mine water inrush sources based on fuzzy evaluation of hydrochemical features; Coal Technol. 33(05) 17-20 (in Chinese).

Xu N, Gong J and Yang G 2018 Using environmental isotopes along with major hydro-geochemical compositions to assess deep groundwater formation and evolution in eastern coastal China; J. Contam. Hydrol. 208 1-9, https://doi. org/10.1016/j.jconhyd.2017.11.003.

Yang Y, Li J, Yue J and Zhao L 2016 Study on PCA-LDA for fast identifying the type of coal mine water with LIF technology; Chem. Eng. Trans. 51 1135-1140, https://doi. org/10.3303/cet1651190.

Yi P, Yang J, Wang Y, Mugwanezal V D P, Chen L and Aldahan A 2018 Detecting the leakage source of a reservoir using isotopes; J. Environ. Radioact. 187 106-114, https:// doi.org/10.1016/j.jenvrad.2018.01.023.

Yu K, Yang Y and Zhang C 2007 Application of fuzzy comprehensive evaluation method in identifying watersource of water-rush in underground shaft; Metal Mine 42(03) 47-50 (in Chinese).

Yurtsever Y 1975 Worldwide survey of stable isotopes in precipitation; Rep. Sect. Isotope Hydrol. 1-40.

Zhang G, Deng W, He Y and Ramsis S 2006 Hydrochemical characteristics and evolution laws of groundwater in Songnen Plain, Northeast China; Adv. Water Sci. 17(01) 20-28 (in Chinese).

Zhang J, Li Y, Lin M, Sun L, Du Z and Li J 2014 Hydrogeochemistry characteristics and source identification: A case study in the Zhangji coal mine in Huainan; Hydrogeol. Eng. Geol. 41(06) 32-37 +50 (in Chinese).

Zhou J, Shi X and Wang H 2010 Water-bursting source determination of mine based on distance discriminant analysis model; J. China Coal Soc. 35(02) 278-282 (in Chinese). 